\title{
CANNABIS(BHANG, CHARAS) CONSUMPTION; EMOTIONAL AND COGNITIVE DISTURBANCES AND DEPRESSIVE SYMPTOMS IN YOUNG ADULTS
}

Head of Department of Applied Psychology,

Government College Township Lahore

Correspondence Address: Dr. Fauzia Naz,

246. M. Income Tax officers' colony, Model Town, Lahore.

fauziakaramat@gmail.com

Article received on: 29/01/2016

Accepted for publication: 30/03/2016

Received after proof reading: 04/05/2016

\begin{abstract}
Dr. Fauzia Naz
ABSTRACT... Cannabis or marijuana is an illegal drug that is being used mostly by young adults can have adverse effects i.e., dependence syndrome, impaired respiratory and cardiovascular functions, psychosocial and mental health disorders. Objective: The present study examined the effects of cannabis (including bhang \& charas) consumption on emotional and cognitive disturbances and depressive symptoms in young adults who use cannabis. The research further explored that cannabis consumption frequency will mediate between emotional and cognitive disturbances and depressive symptoms in young adults. Study Design: Correlational research design. Settings: Lahore city. Method: Sample included 200 young adults who used cannabis in routine and 200 young adults who did not consume any kind of substance. The age range of the sample was between 20 years to 27 years. Snowball sampling technique was used to recruit sample. The comparison group was matched on age, education and socioeconomic status. Cognitive Failure Questionnaire ${ }^{1}$, Emotional Regulation Scale ${ }^{2}$ and Patient Health Questionnaire ${ }^{3}$ were used as assessment measures. Results: Results showed that young adults who use cannabis had higher emotional and cognitive disturbances and had more depressive symptoms compared to the normal controls. There was a significant positive relationship and association between cannabis consumption and emotional and cognitive disturbances and depressive symptoms. Cannabis consumption had mediating relationship between cognitive and emotional disturbances and depressive symptoms. Implications of the study along with strengths and limitations of the current study are discussed.
\end{abstract}

Key words: Cannabis, emotional deregulation, cognitive disturbances

Article Citation: Naz F. Cannabis (Bhang, Charas) consumption; emotional and cognitive disturbances and depressive symptoms in young adults. Professional Med J 2016;23(5):597-602. DOI: 10.17957/TPMJ/16.3272

\section{INTRODUCTION}

Cannabis or marijuana usage is a problematic pattern of cannabis use leads to clinically significant impairment in memory, cognition and emotions with severe symptoms of distress or depression. ${ }^{4}$ Laboratory experiments confirm the dose related effects of cannabis are impairment in the perception of information processing and reaction time, distortion in perceptual motor performance and coordination, deficits in attention and tracking behaviors. ${ }^{5,6}$ Further the researchers ${ }^{7}$ found poor interpersonal relationships, parental history of substance abuse, rebelliousness, low academic attainment and withdrawal symptoms including anxiety, depression, poor appetite and insomnia in young adults. ${ }^{8}$

According to United Nations office on Drugs and Crime $^{9}$ (UNODC; 2013), cannabis usage is highest
(3.6\%) in young adults in Pakistan which is four million people. Cannabis is the highest frequently used illegitimate drug in Pakistan. Pakistan is among one of the biggest manufacturers and traffickers of cannabis carried out via Central Asia and Middle East to Europe, North America and Africa. Cannabis nurtures wild in many regions of the country and formal farming is also extensive. ${ }^{10}$

Pakistan is an Islamic country and any kind of drug consumption is completely illegal and is prohibited by Islam as well as state laws. But contrary to this, being a largely rural/agricultural country, cannabis gardening is common for intoxication purposes. Besides, cannabis is a kind of self-growing plant which can be found in suburbs without formal farming. Cannabis usage is permissible in several areas and segments of the country. In some areas of Pakistan, it is reported that the usage 
of cannabis is as widespread especially in men, as alcohol intake in West, and is ill-conceived to be less problematic than alcohol. Young adults use cannabis for relaxation, euphoria, time distortion and acceleration of usual experiences like spending times with friends, eating, enjoying movies, music and sex related activities. ${ }^{11}$

In a research conducted in Pakistan, the researchers focused on to explore psychotic features in individuals who use cannabis. The researchers found bhang induced symptoms of excitement, grandiosty, disorientation, hostility, uncooperativeness, hallucinations and distorted thought content. The researchers also found manic symptoms with paranoid psychotic features and dysfunctions in cognition. ${ }^{12}$

Abel ${ }^{13,14}$ reported that cannabis usage for recreational activities by adolescents and young adults has been increased over the past fifty years, in social settings to increase sociability and produce euphoric and intoxicating effects. The UN office on Drugs and Crime $^{15}$ has assessed that cannabis usage in developed countries is highest as the intake was estimated by 165 million adults which are estimated $4 \%$ of the world population aged 15-64 years. Statistics indicated that in USA, about ten percent of cannabis users are daily users which is heavy cannabis usage and the start of using cannabis in early to late adolescence is above normal while it peaks in the young adults. ${ }^{15}$

Previous literature has shown strong association of frequency of cannabis usage with increased risks of psychiatric disorders as in their 15-year follow-up study ${ }^{16}$ with Swedish eighteen years men found that men who use cannabis frequently were 2.4 times more likely to be diagnosed with schizophrenia in comparison with those who did not use and risk increase with the cannabis usage frequency. In another 27 years follow up study ${ }^{17,18}$, the sample was studied for 18 years, found a relationship and association between cannabis usage frequency and risk of schizophrenic symptoms. The researchers concluded that thirteen percent of schizophrenia cases could be prevented if cannabis is banned.
These findings have been supported by many of the longitudinal studies in Germany, Netherlands and New Zealand ${ }^{19}$ (Fergusson, Horwood, SwainCampbell, 2003) and a meta-analysis of these longitudinal researches stated a shared OR of $1.3(95 \% \mathrm{Cl} 1 \cdot 15-1 \cdot 44)$ of psychotic features or symptoms in young people/adults who used cannabis. ${ }^{20}$

\section{Hypotheses of the study}

The present study assumed that:

1. Young adults who use cannabis will have higher emotional and cognitive disturbances and depressive symptoms in comparison with those who do not use cannabis.

2. Cannabis consumption frequency will be associated with emotional deregulation, cognitive disturbances and depressive symptoms.

3. Cannabis consumption frequency will likely to mediate between emotional and cognitive disturbances and depressive symptoms in young adults who use cannabis.

\section{METHOD}

\section{Participants}

Sample recruited 200 young men who use cannabis in routine and 200 young men who do not consume any kind of substance through snowball sampling. The age range of the sample was between 20 years to 27 years. The comparison group was matched on age, education and socioeconomic status. Only those adults were included who use cannabis, belong to intact families, do not have any physical disabilities and do not have any diagnosed psychological disorder. The control group was matched with all criteria except they do not use any kind of drugs. Mean education of participants was up to grade 12. Monthly income of participants was between Rs. 38000-39000.

\section{Ethical Considerations}

Research ethics included taking permission from the authors to use tools for this research particularly. Participants were informed about the objectives of the research and were given informed consent forms to participate in research. The participants were told that participation in the 
study is voluntary and they can withdraw from participation anytime they want.

\section{ASSESSMENT MEASURES}

\section{Substance Abuse Scale}

It is a ten items scale used to measure the frequencies of drugs (cannabis). The response options of the questions are "Yes and No" which are given "2" and " 1 " respectively. The score of 20 determine maximum use and the score of 10 shows minimum use.

\section{Cognitive Failure Questionnaire ${ }^{1}$}

(CFQ; $\alpha=$.85-.89). CFQ is a 25 items questionnaire which assesses the frequency of everyday slips and errors such as forgetting appointments and minor mistakes which show cognitive failure. This is a 5 point Likert-type scale. The response options range from very often (4) to never (0). The highest score is 100 which shows severe cognitive failure. The alpha reliability of CFQ for the present research was .83 .

\section{Emotional Regulation Questionnaire (ERQ; Gross \& John, 2003)}

is a ten items self-report questionnaire which measures emotion-regulatory processes. The responses are rated on 7-point Likert scale from "strongly disagree" to "strongly agree". ERQ has good value of internal consistency i.e., .792. For the present research, the alpha reliability was sufficient i.e., .87.

\section{Patient Health Questionnaire (PHQ-9) ${ }^{3}$}

PHQ-9 is a nine items questionnaire which assesses the severity of depressive symptoms for the last two weeks. The response options are not at all (1), several days (1), more than half the days (2) and nearly every day (3). The maximum score is
27 which show severe depression. Alpha reliability of the questionnaire for this study was .88 .

\section{Demographic information form}

This form included information related to age, education, profession, birth order, number of siblings, family system and monthly income of family.

\section{Procedure}

All the assessment measures were finalized and the sample was recruited from different parts of Lahore city. Most of the sample was recruited through snow ball sampling. Initially, 236 young adults who use cannabis agreed to participate in the study but only 200 completed the questionnaires. The comparison group included friends or relatives (brother or cousin brother) as the comparison group was to be matched with age, education and socio-economic status. After completing the assessment procedure, the data were analyzed and results were discussed.

\section{RESULTS}

To test the differences between young adults who use cannabis and those who do not use cannabis on emotional deregulation, cognitive disturbances and depressive symptoms, independent t-test was used.

Results show significant mean differences in the mean scores of two groups i.e., young adults who use cannabis frequently and the comparison group. Mean scores of young adults who use cannabis is higher on emotional deregulation, cognitive disturbances and depressive symptoms as compared to the young adults who do not use cannabis.

\begin{tabular}{|c|c|c|c|c|c|c|}
\hline \multirow[t]{2}{*}{ Variables } & \multicolumn{2}{|c|}{$\begin{array}{l}\text { Young Adults who use } \\
\text { Cannabis }(n=200)\end{array}$} & \multicolumn{2}{|c|}{$\begin{array}{l}\text { Young Adults who do not } \\
\text { use Cannabis }(n=200)\end{array}$} & \multirow[b]{2}{*}{$\mathbf{t}$} & \multirow[b]{2}{*}{$\mathbf{p}$} \\
\hline & M & SD & $\mathbf{M}$ & SD & & \\
\hline Cognitive disturbances & 66.34 & 16.18 & 24.19 & 15.34 & 2.49 & .001 \\
\hline Depressive symptoms & 20.90 & 1.78 & 13.29 & 2.82 & .39 & .001 \\
\hline
\end{tabular}




\begin{tabular}{|l|l|l|l|l|l|l|l|}
\hline \multicolumn{1}{|c|}{ Predictors } & $\mathbf{R}^{2}$ & B & SE & Wald & OR (95\% Cl) & p \\
\hline 1 & Emotional deregulation & .48 & .22 & .03 & 60.23 & $1.05(1.11-1.20)$ & .001 \\
\hline 2 & Cognitive disturbance & .36 & .19 & .04 & .37 .22 & $1.18(1.13-1.20)$ & .001 \\
\hline 3 & Depressive symptoms & .32 & .15 & .01 & 14.36 & $1.06(1.03-1.13)$ & .001 \\
\hline
\end{tabular}

Table-II. Association of Emotional Deregulation, Cognitive Disturbances and Depressive Symptoms with Group of Young Adults who use Cannabis $(\mathrm{N}=400)$

Note. OR: Odd Ratio; Cl: Confidence Interval.

To test the association between emotional deregulation, cognitive disturbances and depressive symptoms with the frequency of cannabis usage, logistic regression analyses were carried out. The two groups were re-categorized i.e., young adults who use cannabis frequently were given the value of 1 and comparison group i. e., young adults who do not use cannabis were given the value of 0 . As the value of 0 should be assigned to whichever response indicates a lack of the characteristic of interest (young adults who do not use cannabis) and the value of 1 should be assigned to whichever response indicates presence of characteristic.

To test the severity of cannabis consumption as mediating variable between emotional and cognitive disturbances and depressive symptoms in young adults, mediation Analysis through Regression analysis was employed. Firstly simple regression analysis was conducted to see cannabis usage frequency as a predictor of emotional deregulation and cognitive disturbances in young adults who use cannabis frequently. Secondly, multiple regression analysis was used to see cannabis usage frequency, emotional deregulation and cognitive disturbances as predictors of depressive symptoms in young adults who use cannabis frequently. The results are presented in table III and table IV.

\begin{tabular}{|l|c|c|c|}
\hline Outcome Variable & $\mathrm{R}^{2}$ & $\Delta \mathrm{R}^{2}$ & $\beta$ \\
\hline Emotional deregulation & $.32^{\star \star}$ & $.32^{\star \star}$ & $.57^{\star \star}$ \\
\hline Cognitive disturbances & $.25^{\star \star}$ & $.25^{\star \star}$ & $.50^{\star \star}$ \\
\hline
\end{tabular}

Table III. Regression Analyses (enter method) for Cannabis Usage Frequency as a predictor of Emotional Deregulation and Cognitive Disturbances in Young Adults who use Cannabis $(\mathrm{N}=200)$. ${ }^{* *} p<.01$.

Results from regression analysis show cannabis usage frequency emerged as significant predictor of emotional deregulation and cognitive disturbances in young adults who use cannabis.

\begin{tabular}{|c|c|c|c|}
\hline Predictors & $\mathbf{R}^{2}$ & $\Delta \mathbf{R}^{2}$ & $\beta$ \\
\hline \multicolumn{4}{|l|}{ Step 1} \\
\hline Cannabis usage frequency & $.26^{\star \star \star}$ & $.26^{\star \star \star}$ & $.50^{\star \star \star}$ \\
\hline \multicolumn{4}{|l|}{ Step2 } \\
\hline Cannabis usage frequency & $.23^{\star \star \star}$ & $.23^{\star \star \star}$ & $.47^{\star \star \star}$ \\
\hline Emotional deregulation & $.32^{* *}$ & $.32^{\star \star}$ & $.57^{\star \star \star}$ \\
\hline \multicolumn{4}{|l|}{ Step3 } \\
\hline Cannabis usage frequency & $.12^{* *}$ & $.12^{* *}$ & $.35^{* *}$ \\
\hline Emotional deregulation & $.13^{\star \star}$ & $.13^{\star \star}$ & $.36^{\star *}$ \\
\hline Cognitive disturbances & $.41^{* \star \star}$ & $.41^{\star \star \star}$ & $.28^{* *}$ \\
\hline \multicolumn{4}{|c|}{$\begin{array}{l}\text { Table IV. Hierarchical Regression Analyses (enter } \\
\text { method) for Frequency of Cannabis Use, Emotional } \\
\text { Deregulation and Cognitive Failures as predictors } \\
\text { of Depressive Symptoms in Young Adults who use } \\
\text { Cannabis }(\mathrm{N}=200) \text {. } \\
{ }^{* *} p<.01 .{ }^{* *} p<.001 .\end{array}$} \\
\hline
\end{tabular}

Results reveal that hierarchical regression worked out in three steps. Cannabis usage frequency, emotional deregulation and cognitive disturbances emerged as significant predictor of depressive symptoms.

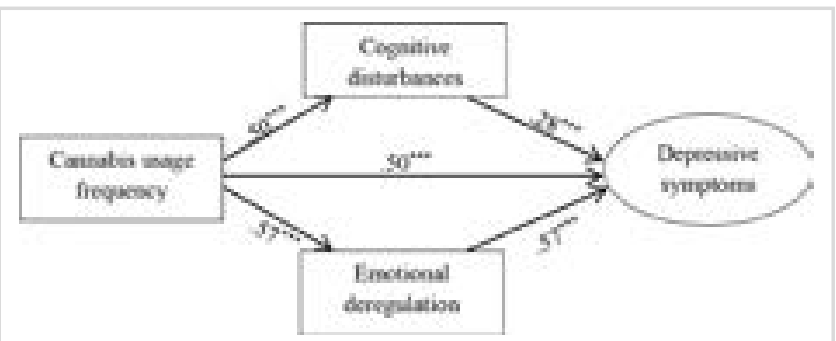

Figure 1: Hierarchical Regression Model for Prediction

\section{DISCUSSION}

The present study came up addressing multiple aims. Firstly, the study examined the effects of cannabis (including bhang \& charas) consumption on emotional and cognitive disturbances and 
depressive symptoms in young adults who use cannabis. Results revealed mean scores of young adults who use cannabis was higher on emotional deregulation, cognitive disturbances and depressive symptoms as compared to the young adults who do not use cannabis. Results also revealed significant association of cannabis usage frequency (group who used cannabis) with emotional deregulation, cognitive disturbances and depressive symptoms.

The mediation model confirmed the mediating relationship of cannabis usage frequency between emotional deregulation and cognitive disturbances and depressive symptoms in young adults who use cannabis.

These results are in agreement with the findings of a research ${ }^{12}$ in which the researchers found bhang induced symptoms included excitement, grandiosity, disorientation, hostility, uncooperativeness, hallucinations and distorted thought content. The researchers also found manic symptoms with paranoid psychotic features and dysfunctions in cognition. Similarly, previous studies ${ }^{21}$ which show that cannabis consumption has adverse effects on health. Besides dependence syndrome, the cannabis consumption was found to be associated with not only physical adverse outcomes but also with adverse mental health and put forward the conclusion that consistent use of cannabis can lead to adverse effects including dependence syndrome, impaired respiratory and cardiovascular functions, psychosocial and mental health disorders. In other laboratory based experiments, the researchers ${ }^{5}$ pointed out that the dose related effects of cannabis in laboratory experiments included impairment in the perception of information processing and reaction time, distortion in perceptual motor performance and coordination, deficits in attention and tracking behaviors. ${ }^{6}$ While a history of poor academic achievement, rebelliousness, poor interpersonal relationships especially with parents and a parental history of drug and alcohol problems, withdrawal symptoms i.e., anxiety, depression, poor appetite and insomnia were reported in young adults. ${ }^{7,8}$

\section{CONCLUSION}

While reviewing the literature for the commencement of current study, scarce researches were found and those were conducted in early nineteen nineties (1991) but no current trends have been found to identify the effects (especially psychological/mental) of cannabis consumption. Present study is the first study in which effects of cannabis consumption i.e., emotional deregulation, cognitive disturbances and depressive symptoms were explored. Cannabis consumption has significant effects on emotional deregulation, cognitive disturbances and depressive symptoms. Cannabis usage frequency has association with emotional deregulation, cognitive disturbances and depressive symptoms and has mediating relationship with emotional deregulation, cognitive disturbances and depressive symptoms.

\section{Copyright@ 30 March, 2016.}

\section{REFERENCES}

1. Broadbent DE, Cooper PF, Fitzgerald P, Parkes KR: The cognitive failure questionnaire (CFQ) and its correlates. British Journal of Clinical Psychology.1982; 21:1-16.

2. Gross JJ, John OP: Individual differences in two emotion regulation processes: Implications for affect, relationships, and well-being. Journal of Personality and Social Psychology. 2003; 85: 348-362.

3. Spitzer LR, Williams BJ, Kroenke K, et al. Patient Health Questionnaire. Pfizer Inc 2002.

4. American Psychological Association: Diagnostic and statistical manual of mental disorders (5th ed.). Washington, DC: Author. 2013.

5. Ramaekers JG, Berghaus G Van Laar M, Drummer $\mathrm{OH}$ : Dose related risk of motor vehicle crashes after cannabis use. Drug Alcohol Depend. 2004;73:109-119.

6. Solowij N, Cannabis and cognitive functioning. Cambridge, UK: Cambridge University Press. 1998.

7. Budney AJ, Hughes JR (2008). The cannabis withdrawal syndrome. Current Opinion Psychiatry. 2008; 19: 233-38.

8. Anthony JC, The epidemiology of cannabis dependence. In: Roffman, R. A., Stephens, R. S., eds. Cannabis dependence: its nature, consequences and 
treatment. Cambridge, UK: Cambridge University Press, 2006: 58-105.

9. United Nations Office of Drug \& Crime. Report on Drug Use in Pakistan in 2013. The International Drug Control Conventions, 2013; ISBN 978 -92-1-148248-5.

10. Seshata, Cannabis in Pakistan. 2014. sensiseeds. com.Cannabis News retrieved from http:// sensiseeds.com/en/blog/cannabis-in-pakistan/.

11. Green B, Kavanagh D, Young R, Being stoned: a review of self-reported cannabis effects. Drug Alcohol Rev, 2010; 22: 453-60.

12. Chaudry HR, Moss HB, Bashir A: Cannabis psychosis following bhang ingestion. British Journal of Addiction, 1991; 86: 1075-1081.

13. Abel EL, Marihuana: the first twelve thousand years. New York: Plenum Press, 1980.

14. Hall WD, Degenhardt L: Prevalence and correlates of cannabis use in developed and developing countries. Current Opinion Psychiatry, 2007; 20: 393-397.

15. United Nations Office of Drugs \& Crime. (UNODC) World drug report. Analysis. Vienna, 2006.
16. Hall WD, Pacula RL: Cannabis use and dependence: public health and public policy. Cambridge, UK: Cambridge University Press, 2003.

17. Andreasson S, Allebeck $P$, Engstrom A, Rydberg U,(1987). Cannabis and schizophrenia. A longitudinal study of Swedish conscripts. Lancet 1987; 2:1483-1486.

18. Zammit $S$, Allebeck $P$, Andréasson $S$, Lundberg I, Lewis G, Self-reported cannabis use as a risk factor for schizophrenia in Swedish conscripts of 1969: historical cohort study. Evidence Based Mental Health Journal, 2002; 325: 1199-201.

19. Fergusson DM, Horwood LJ, Swain-Campbell NR: Cannabis dependence and psychotic symptoms in young people. Psychol Med 2003;33:15-21.

20. Moore TH, Zammit S, Lingford-Hughes A, et al. (2007). Cannabis use and risk of psychotic or affective mental health outcomes: a systematic review, 2007;370: 319-328.

21. Hall WD, Degenhardt L: (2009). Adverse health effects of non-medical cannabis use. Lancet, 2009; 374: 1383-1391.

\section{"If you want something you never had you have to do something you've never done."}

AUTHORSHIP AND CONTRIBUTION DECLARATION

\begin{tabular}{|c|c|c|c|}
\hline Sr. \# & Author-s Full Name & \multicolumn{1}{c|}{ Contribution to the paper } & Author=s Signature \\
1 & Dr. Fauzia Naz & $\begin{array}{l}\text { Conceived, designed and } \\
\text { collected data, analyzed } \\
\text { data, results, discussion } \\
\text { and references. }\end{array}$
\end{tabular}

